\section{Evaluation of Onion Genotypes for Resistance to Stunting Caused by Rhizoctonia solani AG 8}

\author{
Dipak Sharma-Poudyal ${ }^{1}$ \\ Department of Plant Pathology, Washington State University, Pullman, WA \\ 99164
}

Timothy C. Paulitz
United States Department of Agriculture, Agriculture Research Service,
Pullman, WA 99164

Lindsey J. du Toit ${ }^{2}$

Department of Plant Pathology, Washington State University Mount Vernon NWREC, Mount Vernon, WA 98273

Additional index words. root pathogen, disease resistance, Columbia Basin

\begin{abstract}
Thirty-five onion genotypes were evaluated for resistance to stunting caused by Rhizoctonia solani anastomosis group 8 (AG 8) in a growth chamber set at $15 \pm 1^{\circ} \mathrm{C}$. The trial was repeated. Resistance to $R$. solani AG 8 was defined as a lack of significant difference in plant height, root length, and/or total dry biomass between inoculated and noninoculated plants of the same genotype. Plant height was not reduced significantly by $R$. solani AG 8 for 14 and 7 of the 35 genotypes in Trials 1 and 2, respectively. In Trial 1, plant height reduction caused by $R$. solani ranged from $24 \%$ for the cv. Lasalle to $62 \%$ for the experimental line R14882, and in Trial 2 plant height reduction ranged from $22 \%$ for the experimental line PX07713218 to $53 \%$ for the cv. Montblanc. However, the extent of reduction in plant height caused by $R$. solani did not differ significantly among genotypes in either trial. Onion root length was not reduced by $R$. solani AG 8 for 26 and 18 of the 35 genotypes in Trials 1 and 2, respectively. The degree of reduction in root length ranged from 9\% (R14889) to 76\% (Sterling and SN232) in Trial 1, and $14 \%(\mathrm{SN} 325)$ to $74 \%$ (Sterling) in Trial 2. Onion dry biomass was not reduced by $R$. solani AG 8 for 19 and 7 of the 35 genotypes in Trials 1 and 2, respectively, and ranged from 18\% (Elbrus) to 69\% (Sterling) in Trial 1, and 29\% (SN232) to 79\% (Sterling) in Trial 2. The reduction in onion root length and total biomass did not differ significantly among onion genotypes in Trial 1, but differed among genotypes in Trial 2 . Of the 35 genotypes evaluated, 3, 16, and 3 demonstrated partial resistance to $R$. solani AG 8 for plant height, root length, and total biomass, respectively, in both trials. Only four genotypes displayed partial resistance to R. solani AG 8 for at least two of the three growth parameters: plant height, root length, and biomass of PX07713218 were unaffected by the fungus in either trial; and R14885, R14888, and SN307 displayed partial resistance in both trials for two of the three parameters, and in one of the two trials for the third parameter. These four genotypes could be used in onion breeding programs to develop cultivars partially resistant to stunting caused by $R$. solani AG 8 .
\end{abstract}

Received for publication 29 Dec. 2014. Accepted for publication $11 \mathrm{Feb} .2015$.

This research was supported financially by the Pacific Northwest Vegetable Association, the Washington State Commission for Pesticide Registration, a Specialty Crop Block Grant from the Washington State Department of Agriculture, and Washington State University Department of Plant Pathology (PPNS No. 0671) as well as the College of Agricultural, Human, and Natural Resource Sciences Agricultural Research Center (Hatch Project No. 0595), Pullman, WA. The authors thank Bejo Seeds, Inc.; Seminis Vegetable Seeds; and Bayer CropScience Vegetable Seeds for providing seeds of onion genotypes for this study.

${ }^{1}$ Present address: Plant Health Program, Oregon Department of Agriculture, Salem, OR.

${ }^{2}$ To whom reprint requests should be addressed; e-mail dutoit@wsu.edu.
Rhizoctonia solani causes stunting of onion (Allium cepa L.) in the coarse, sandy soils of the semiarid Columbia Basin of Oregon and Washington States (Patzek et al., 2013). The disease occurs in the cereal-onion cropping systems of this region when cereals such as winter wheat (Triticum aestivum L.) or barley (Hordeum vulgare L.) are planted as cover or windbreak crops in the fall and then killed with herbicide applications just before seeding onion crops the following spring (Patzek et al., 2013; Sharma-Poudyal et al., 2013a). The dead windbreak cereal crop protects onion seedlings against sand blasting during very windy spring conditions typical of the Columbia Basin (Pelter and Sorensen, 2003). When the cereal crops are tall enough to limit soil erosion for the onion crop in spring, an herbicide is applied to kill the cover crop
(Pelter and Sorensen, 2003; Sharma-Poudyal et al., 2013a). The dying cereal roots provide a substrate for saprophytic growth of the fungal pathogen $R$. solani, particularly strains of anastomosis group (AG) 8 , which then rapidly colonize the dying cereal roots, resulting in a significant increase in soilborne inoculum (Babiker et al., 2011; Sharma-Poudyal et al., 2013a). Consequently, this inoculum can lead to infection of the roots of onion seedlings growing adjacent to the dead wheat plants, which can result in significant stunting of onion plants in patches in the field (SharmaPoudyal et al., 2013a).

Onion seedlings infected with $R$. solani AG 8 develop pinched-off or "spear-tipped" roots as early as the first true-leaf stage, although the patches of stunted onion plants usually only become visible at the three- to five-true-leaf stage (Sharma-Poudyal et al., 2015). Anecdotal evidence from growers and crop consultants suggests that stunted patches can develop on any of the onion cultivars commonly grown in the Columbia Basin. The patches of stunted seedlings can range from $<1 \mathrm{~m}$ to $>25 \mathrm{~m}$ in diameter and, in severe circumstances, patches may comprise up to $15 \%$ of an onion field (du Toit, 2009; du Toit et al., 2012; Wicks et al., 2011). Severely infected seedlings remain stunted relative to adjacent healthy plants throughout the season. Although $R$. solani AG 8 infects onion plants during the seedling phase of growth, the infections do not affect plant stand (Patzek et al., 2013). Therefore, the numbers of bulbs harvested from stunted patches vs. healthy areas of the field do not differ (Sharma-Poudyal et al., 2013b; SharmaPoudyal et al., 2015) but bulb size and marketable yield are affected adversely (Anstis et al., 2012; du Toit et al., 2012; Sharma-Poudyal et al., 2013b; Sharma-Poudyal et al., 2015). In a yield loss survey in the Columbia Basin in 2012 and 2013, stunted patches in onion crops caused up to $78 \%$ reduction in bulb yield within the patches of stunted plants. The pathogen significantly reduced marketable bulb yield within stunted patches compared with adjacent healthy areas of the field for each of six storage-type cultivars evaluated: Cometa (Bayer CropScience Vegetable Seeds, Brooks, OR), Frontier (American Takii, Salinas, CA), Legend (Bejo Seeds, Inc.), Mercury (Seminis Vegetable Seeds, Parma, ID), Tamara (Bejo Seeds, Inc., Oceano, CA), and Redwing (Bejo Seeds, Inc.). The degree of reduction in marketable bulb weight within stunted patches increased as severity of stunting increased. Marketable bulb weight in patches with a stunting severity rating of 1 (majority of onion plants in the patch were stunted $\leq 33 \%$ compared with adjacent plants outside the patch) ranged from $10 \%$ to $47 \%$, in patches with a severity rating of 2 (majority of onion plants stunted $33 \%$ to $66 \%$ ) ranged from $24 \%$ to $57 \%$, and in patches with a severity rating of 3 (majority of plants stunted $>66 \%$ ) ranged from $40 \%$ to $78 \%$. Average reduction in total marketable bulb yield in the stunted patches was $42 \%$ (Sharma-Poudyal et al., 2013b; Sharma-Poudyal et al., 2015). 
The yield loss study by Sharma-Poudyal et al. (2015) demonstrated that onion cultivars commonly grown in the Columbia Basin can incur significant yield loss from stunting. Due to the increasing prevalence of this disease in the Columbia Basin over the last 10 years, which is one of the major onion producing regions of the United States (USDA NASS, 2012), information on the relative resistance or susceptibility of onion cultivars to this disease could be useful for identifying $R$. solani AG 8-resistant onion cultivars for planting in high-risk fields in this region. Therefore, the objective of this study was to evaluate onion genotypes for relative resistance to $R$. solani AG 8 . The cultivars or genotypes were obtained from seed companies that commonly produce intermediate- to long-day storage type onions suitable for the semiarid Columbia Basin.

\section{Materials and Methods}

Screening of onion genotypes. Isolate Rh070927 of $R$. solani AG 8 was used for this study. The isolate was obtained originally from roots of a symptomatic (stunted) onion plant in the Columbia Basin of Oregon, and demonstrated to be pathogenic on onion (Patzek et al., 2013). Inoculum of $R$. solani AG 8 was increased, prepared, and quantified as described by Paulitz and Schroeder (2005). In summary, $500 \mathrm{~cm}^{3}$ of whole oat (Avena sativa) kernels were mixed with $500 \mathrm{ml}$ distilled water in 2-L glass flasks, and sealed with aluminum foil. Each flask was autoclaved twice for $90 \mathrm{~min}$, about $24 \mathrm{~h}$ apart. The sterilized oats in each flask were then inoculated with 5-mm-diameter colonized agar plugs taken from a 1-week-old potato dextrose agar culture of $R$. solani AG 8. Flasks were incubated in the dark at $25^{\circ} \mathrm{C}$ for 6 weeks. The contents in each flask were shaken once a week to facilitate complete colonization of the oat kernels. The inoculum was air-dried on Kraft paper and then stored in plastic zip-lock bags at $4{ }^{\circ} \mathrm{C}$ in the dark until quantification and use. Within a few days of an experiment, oat inoculum was ground in a coffee grinder and sieved to obtain particle sizes of 250 to $1000 \mu \mathrm{m}$ diameter. Inoculum density was quantified by dilution plating onto $2 \%$ water agar.

A sandy loam soil collected from an uncultivated portion of a grower-cooperator's field in the Columbia Basin was steampasteurized for $1 \mathrm{~h}$ at $60^{\circ} \mathrm{C}$, and steamed again for the same duration $24 \mathrm{~h}$ later. The soil was then air-dried on Kraft paper, sieved to a particle size of $\leq 2 \mathrm{~mm}$, and stored in buckets sealed with airtight lids. Four seeds of each of the onion genotypes or cultivars were planted in a plastic cone-tainer (cone-shaped, 4-cm diameter, and 21-cm long; Steuwe and Sons, Inc., Tangent, OR) filled with $150 \mathrm{~g}$ of pasteurized soil. Ground $R$. solani AG 8-colonized oat seeds $(1 \% \mathrm{w} / \mathrm{w}$ for a total soil weight) (Paulitz and Schroeder, 2005) were mixed with the soil and then saturated with $50 \mathrm{ml}$ of water just before planting.

Thirty-five onion genotypes or cultivars (9 from Bejo Seeds, Inc., Oceano, CA; 17 from Bayer CropScience Vegetable Seeds, Parma, ID; and 9 from Seminis Vegetable Seeds, Inc., Oxnard, CA) were tested for relative resistance to $R$. solani $\mathrm{AG} 8$ in a growth chamber set at $15 \pm 1{ }^{\circ} \mathrm{C}$ (Table 1). The four seeds planted in each of five replicate conetainers were covered with a thin layer $(8 \mathrm{~g})$ of pasteurized soil. Five replicate cone-tainers without $R$. solani AG 8 served as a control treatment for each onion genotype, to provide a $35 \times 2$ factorial (inoculation $\times$ onion genotype, respectively) treatment design. Conetainers were arranged in a randomized complete block design in plastic trays. Each plastic tray was covered with Kraft paper for seven days to conserve soil moisture and promote onion emergence. Plants were irrigated with $25 \mathrm{ml}$ of water and $25 \mathrm{ml}$ of 1/3-strength Hoagland's solution (macroelements only) every 3 to $4 \mathrm{~d}$ until harvest. Onion seedlings in each cone-tainer were thinned to two seedlings 3 weeks after planting. Plant height $(\mathrm{cm})$, root length $(\mathrm{cm})$, and total dry biomass (g) were measured for the two seedlings in each inoculated and noninoculated conetainer for each genotype $45 \mathrm{~d}$ after planting. The experiment was repeated.

Data analysis. Pearson's correlation coefficients for plant height, root length, and total plant biomass were calculated using JMP Version 11 Pro (SAS Institute Inc., Cary, NC). The percentage reduction in plant height, root length, and total biomass of inoculated plants of each onion genotype were calculated as a measurement of disease severity based on plant height, root length, and total biomass of the noninoculated plants of each genotype. Analysis of variance (ANOVA) was used to determine the genotype effect on reduction in plant height, root length, and total biomass using JMP. Data were rank transformed (Conover and Iman, 1981) since the assumptions for parametric analyses were not met even after transforming the data using the Box-Cox transformation approach in JMP. Treatment means were compared by using Fisher's protected least significant difference (LSD). Mean plant height, root length, and total biomass of inoculated vs. control plants of each genotype were compared using Student's $t$ test.

\section{Results and Discussion}

The correlation coefficients for overall reduction in onion plant height, root length, and total biomass of plants inoculated with $R$. solani AG 8 compared with noninoculated plants for all 35 onion genotypes revealed a highly significant correlation of plant height with total plant biomass ( $r=0.79$ and 0.78 at $P<0.001$ in Expt. 1 and 2, respectively) and root length $(r=0.75$ and 0.70 at $P<0.001$ in Expt. 1 and 2, respectively), as well as between root length and total biomass $(r=0.69$ and 0.61 at $P<0.001$ in Expt. 1 and 2, respectively). Disease severity caused by $R$. solani AG 8 was expressed as the degree of stunting (Anstis et al., 2012; Patzek et al., 2013), i.e., the reduction in height of onion plants inoculated with $R$. solani AG 8 vs. that of noninoculated plants of the same genotype.
The average reduction in plant height across the 35 onion genotypes was $40 \% \pm$ $21 \%$ (mean $\pm \mathrm{SD}$ ) in Expt. 1, and 38\% $\pm 15 \%$ in Expt. 2. Although the degree of reduction in plant height ranged from $24 \% \pm 30 \%$ (for the onion cv. Lasalle) to $62 \% \pm 17 \%$ (R14882) in Expt. 1, and $22 \% \pm 40 \%$ (PX07713218) to 53\% $\pm 15 \%$ (Montblanc) in Expt. 2, the reduction in plant height caused by $R$. solani AG 8 did not differ significantly among genotypes in either experiment (Table 1). Comparing inoculated vs. noninoculated plants within genotypes using Student's $t$ test revealed that the height of plants for 14 onion genotypes inoculated with $R$. solani AG 8 in Expt. 1 (Lasalle, PX07713218，R14881，R14883，R14885, R14886, R14887, R14888, SN296, SN307, SN368, SN435, SN483, and SN559), and 7 genotypes in Expt. 2 (PX07713218, R14882, R14888, R14889, SN232, SN272, and SN307) were not reduced by the pathogen, i.e., these genotypes demonstrated potential partial resistance to the pathogen. Of these entries, the height of three (R14888, PX07713218, and SN307) were unaffected by $R$. solani AG 8 in both experiments (Table 1). Nine genotypes in Expt. 1 (Lasalle, Montblanc, R14885, SN325, SN368, SN483, SN435, SN559, and SN709), and 11 genotypes in Expt. 2 (Barbaro, Divino, Elbrus, PX07713218, R14882, R14886, R14888, R14889, SN131, SN232, and SN483) were stunted $\leq 33 \%$ compared with noninoculated plants, which equated to a stunting severity rating of 1 in the onion yield loss study of Sharma-Poudyal et al. (2015). Twenty-six genotypes in Expt. 1 and 24 genotypes in Expt. 2 displayed foliar stunting of $34 \%$ to $62 \%$ and $34 \%$ to $53 \%$, respectively, which equated to a stunting severity rating of 2 as described by Sharma-Poudyal et al. (2015).

The lack of significant differences between inoculated vs. control plants for some genotypes in only one of the two experiments may reflect the limited number of plants evaluated, the large variance in dependent variables measured, and/or inherent variability within some of the genotypes evaluated with $R$. solani AG 8. For example, the reduction in plant height for inoculated plants of R14882 was $62 \% \pm 17 \%$ in Expt. 1, which was highly significant, but was only $26 \% \pm$ $22 \%$ in Expt. 2, which was not significant. However, what is not accounted for in this study is that differences in plant height between inoculated and noninoculated plants of the same genotype likely would have increased if the onions were grown for a longer duration, since severity of stunting in onion bulb crops in the Columbia Basin tends to be expressed most distinctly 2 to 2.5 months after planting, at about the five-true leaf stage of growth in spring-sown onions (Sharma-Poudyal et al., 2015). A stunting severity of $26 \%$ equated to a severity rating of 1 in the yield loss study by SharmaPoudyal et al. (2015), which resulted in a significant reduction in marketable bulb weight of $10 \%$ to $47 \%$ in onion bulb crops in the Columbia Basin, depending on the cultivar and field conditions. 
Table 1. Percent reduction in plant height, root length, and total dry biomass of plants of each of 35 onion genotypes inoculated with the onion stunting pathogen, Rhizoctonia solani anastomosis group 8, compared with noninoculated control plants of each genotype in each of two trials in a growth chamber set at $15 \pm 1{ }^{\circ} \mathrm{C}$.

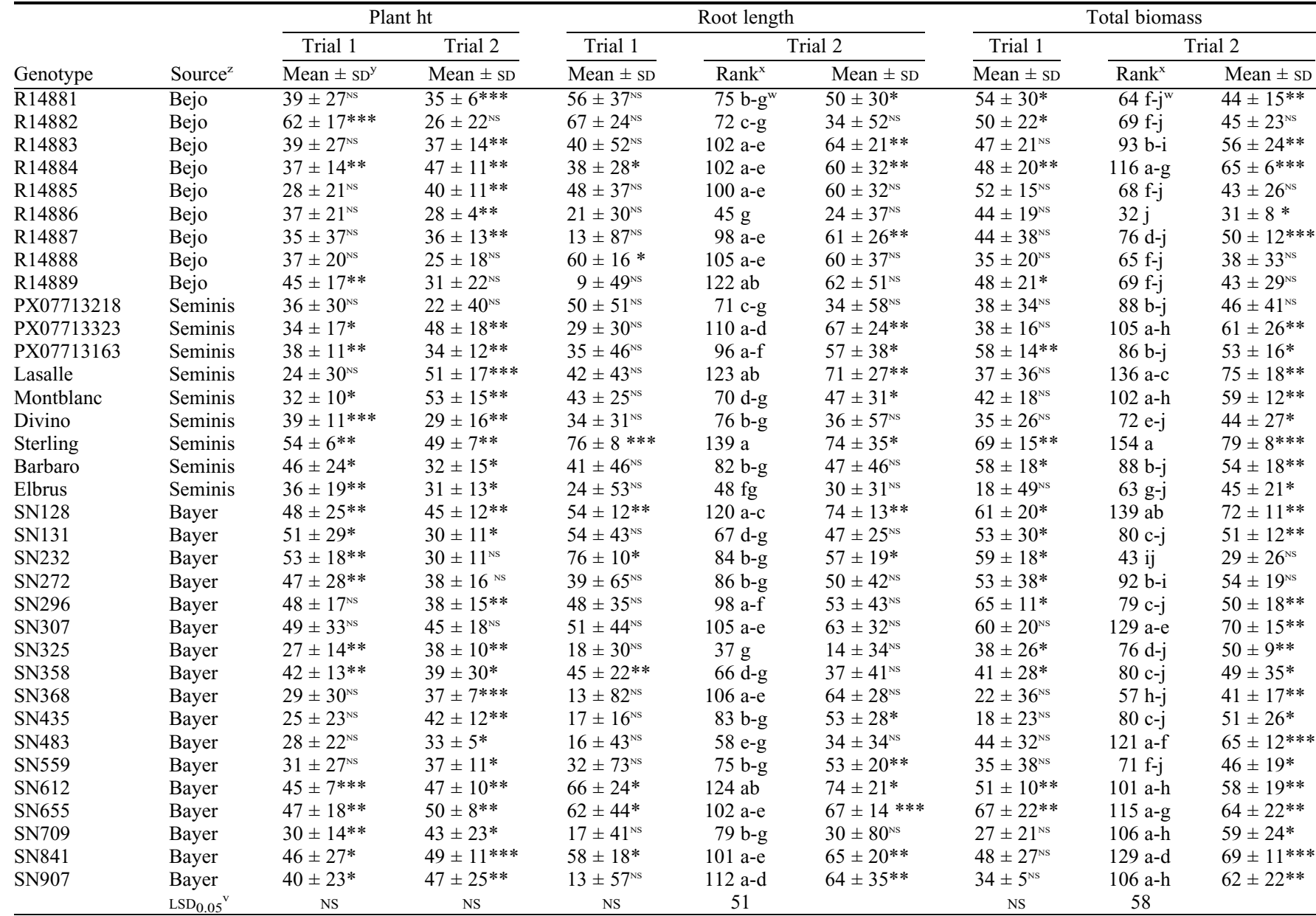

${ }^{\mathrm{z}}$ Seed companies from which seeds were obtained: Bejo Seeds, Inc. (Oceano, CA); Seminis Vegetable Seeds, Inc. (Oxnard, CA); and Bayer CropScience Vegetable Seeds, Inc. (Parma, ID).

${ }^{\mathrm{y}}$ Mean $\pm \mathrm{SD}=$ mean $\pm \mathrm{SD}$ for five replicate inoculated plants, calculated as a percentage of the variable measured for five replicate noninoculated plants of that genotype. Ns, $* * *, * * *$ nonsignificant or significant at $P \leq 0.05,0.01$, or 0.001 , respectively, using Student's $t$ test for comparison of inoculated vs. noninoculated control plants within each genotype.

${ }^{x}$ Rank transformed data when the main effect of onion genotype was significant in the analysis of variance $(P \leq 0.05)$ for that dependent variable.

"Ranked values followed by the same letter are not significantly different $(P \leq 0.05)$ based on Fisher's protected least significant difference (LSD).

${ }^{v} \mathrm{LSD}_{0.05}=$ Fisher's protected least significant difference among genotypes at $P<0.05$ from the analysis of variance for all 35 genotypes.

Growing onion seedlings in soil inoculated with $R$. solani AG 8 resulted in a significant reduction in root length for some genotypes. The average reduction in root length across genotypes was $40 \% \pm 39 \%$ in Expt. 1 , ranging from $9 \% \pm 49 \%$ for R 14889 to $76 \% \pm 10 \%$ for SN232 and $76 \% \pm 8 \%$ for Sterling. In Expt. 2, the average reduction in root length was $52 \% \pm$ $34 \%$, with a range of $14 \% \pm 34 \%$ for SN325 to $74 \% \pm 35 \%$ for Sterling. The extent of reduction in onion root length caused by $R$. solani AG 8 did not differ significantly among genotypes in Expt. 1, but was significant in Expt. 2 (Table 1). Mean root length of inoculated vs. noninoculated control plants was not affected significantly by the pathogen for 26 of the onion genotypes in Expt. 1. SN325 had the least reduction in root length, $14 \% \pm 34 \%$ (which differed significantly from that of 17 other genotypes), and SN232 had the greatest reduction in root length, $57 \% \pm 19 \%$. In Expt. 2, root length of 18 onion genotypes was not reduced significantly by $R$. solani AG 8 . The root length of 16 of the 35 genotypes (Barbaro,
Divino, Elbrus, PX07713218, R14882, R14885, R14886, R14889, SN131, SN272, SN296, SN307, SN325, SN368, SN483, and SN709) was not reduced by $R$. solani AG 8 in either experiment (Table 1), indicating potential partial resistance of these genotypes to root pruning or spear-tipping by this pathogen.

The reduction in total onion plant biomass caused by $R$. solani AG 8 in Expt. 1 ranged from $18 \% \pm 49 \%$ for Elbrus to $69 \% \pm 15 \%$ for Sterling, with an average of $45 \% \pm 24 \%$ among the 35 genotypes (Table 1). However, the reduction in onion biomass caused by $R$. solani AG 8 did not differ significantly among genotypes in Expt. 1. In Expt. 2, reduction in total plant biomass ranged from $29 \% \pm 26 \%$ for SN232 to $79 \% \pm 8 \%$ for Sterling, and averaged $53 \% \pm 19 \%$ across all 35 genotypes, with significant differences among genotypes. In Expt. 1, total plant biomass of 19 onion genotypes was not affected by the pathogen, i.e., did not differ between inoculated and noninoculated plants, whereas in Expt. 2 this was true for only 7 genotypes (Table 1 ). In
Expt. 2, the minimum biomass reduction was $31 \% \pm 8 \%$ for R14886, which did not differ significantly from that of 19 other onion genotypes. Plant biomass of each of PX07713218, R14885, and R14888 was not reduced by inoculation with $R$. solani AG 8 in either experiment (Table 1).

Some onion genotypes (Lasalle, PX07713218, R14883, R14885, R14886, R14887, SN307, SN368, SN435, SN483, and SN559 in Expt. 1; and PX07713218, R14882, R14888, R14889, and SN272 in Expt. 2) showed no significant reduction in plant height, root length, and total biomass when inoculated with $R$. solani AG 8 . The lack of consistency in reactions of some genotypes across the two experiments demonstrated the difficulty of screening onion plants for resistance to this pathogen with a limited number of plants. Screening onion cultivars using a much greater number of plants, and perhaps a range in inoculum levels, could facilitate more robust detection of differences in resistance among genotypes. However, resistance to Rhizoctonia 
spp. in other plant species generally is rare, and diseases caused by Rhizoctonia spp. usually are managed most effectively with disease management strategies other than planting resistant cultivars, e.g., appropriate crop rotations, fungicide seed treatments (Panella and Ruppel, 1996), fungicide soil treatments (SharmaPoudyal et al., 2013c), cultural practices (Sharma-Poudyal et al., 2013a), etc.

Of the 35 genotypes evaluated, 3,16 , and 3 demonstrated partial resistance to $R$. solani AG 8 in both trials for plant height, root length, and total biomass, respectively. Only four genotypes displayed partial resistance to $R$. solani AG 8 for at least two of the three growth parameters: plant height, root length, and biomass of PX07713218 were not affected by the pathogen in either trial; and R14885, R14888 and SN307 displayed partial resistance in both trials for two of the three growth parameters, and in one trial for the third parameter. These four genotypes could be used in onion breeding programs to develop cultivars partially resistant to stunting caused by $R$. solani AG 8 . The fact that a majority of the 35 onion genotypes screened in this study were susceptible to $R$. solani AG 8 corroborates empirical observations of onion growers in the Columbia Basin that all storage type cultivars grown under conditions conducive to onion stunting in this region can develop patches of stunted plants, as well as the yield loss study by Sharma-Poudyal et al. (2015) which documented significant yield reductions caused by onion stunting for each of six cultivars commonly grown in the Columbia Basin. It may be necessary to screen more diverse Allium germplasm, e.g., wild Allium relatives, to identify resistance to onion stunting that can be incorporated into cultivars suitable for the Columbia Basin and other regions of the world where onion stunting occurs, such as Australia (Anstis et al., 2012; Wicks et al., 2011).

\section{Literature Cited}

Anstis, S.T., T.J. Wicks, and S. Pederick. 2012. Rhizoctonia solani AG-8 associated with stunted onion patches in South Australia. Acta Hort. 969:247-253.

Babiker, E.M., S.H. Hulbert, K.L. Schroeder, and T.C. Paulitz. 2011. Optimum timing of preplant applications of glyphosate to manage Rhizoctonia root rot in barley. Plant Dis. 95:304-310.

Conover, W.J. and R.L. Iman. 1981. Rank transformations as a bridge between parametric and nonparametric statistics. Amer. Stat. 35:124-129.

du Toit, L.J. 2009. Rhizoctonia seedling blight of onion in the Columbia Basin. 2009 Washington State University Onion Field Day, Quincy, WA.

du Toit, L.J., D. Sharma-Poudyal, T. Paulitz, L. Porter, J. Eggers, and P. Hamm. 2012. Onion stunting caused by Rhizoctonia: Management and economic importance in the Columbia Basin of Oregon and Washington, p. 68-77. Proc. 2012 Nat. Allium Res. Conf., Las Cruces, NM. 1 Dec. 2014. <http://aces.nmsu. edu/narc2012/index.html $>$.

Panella, L. and E.G. Ruppel. 1996. Availability of germplasm for resistance against Rhizoctonia spp, p. 515-527. In: Rhizoctonia species: Taxonomy, molecular biology, ecology, pathology and disease control. Springer, Netherlands.

Patzek, L.J., L.J. du Toit, T.C. Paulitz, and S.S. Jones. 2013. Stunting of onion in the Columbia
Basin of Oregon and Washington caused by Rhizoctonia spp. Plant Dis. 97:1626-1635.

Paulitz, T.C. and K.L. Schroeder. 2005. A new method for the quantification of Rhizoctonia solani and $R$. oryzae from soil. Plant Dis. 89:767-772.

Pelter, G.Q. and E.J. Sorensen. 2003. Crop profile for onions in Washington. Regional Integrated Pest Management Centers, United States Department of Agriculture.

Sharma-Poudyal, D., T. Paulitz, L. Porter, J. Eggers, P. Hamm, and L.J. du Toit. 2013a. Effect of timing of glyphosate application to a winter cover crop on stunting of spring-sown onions caused by Rhizoctonia spp. in the Columbia Basin of Washington, 2012. Plant Dis. Mgt. Rpt. V046(7)

Sharma-Poudyal, D., T. Paulitz, L. Porter, J. Eggers, P. Hamm, and L.J. du Toit. 2013b. Yield responses of three onion cultivars to stunting caused by Rhizoctonia spp. in the Columbia Basin of Oregon and Washington, 2012. Plant Dis. Mgt. Rpt. V048(7).

Sharma-Poudyal, D., T. Paulitz, L. Porter, J. Eggers, P. Hamm, and L.J. du Toit. 2013c. Efficacy of fungicides to manage onion stunting caused by Rhizoctonia spp. in the Columbia Basin of Oregon and Washington, 2011-2012. Plant Dis. Mgt. Rpt. V047(7).

Sharma-Poudyal, D., T.C. Paulitz, and L. J. du Toit. 2015. Stunted patches in onion bulb crops in Oregon and Washington: Etiology and yield loss. Plant Dis. (In press.)

United States Department of Agriculture National Agricultural Statistics Service. 2012. Vegetables 2011 summary. Tech. Rep. January 2012.

Wicks, T., G. Walker, S. Pederick, and S. Anstis. 2011. Onion stunting in South Australia associated with Rhizoctonia solani AG 8. Australas. Plant Pathol. 40:126-132. 